\section{A PRACTICE OF GENERAL ANAESTHESIA FOR NEUROSURGERY}

By Robert I. W. Ballantine, M.R.C.S., L.R.C.P., D.A., F.F.A.R.C.S., with the collaboration of

IAN JaCkson, M.R.C.S., L.R.C.P., D.A. Pp. viii + I52, with 68 illustrations. London: J. \& A. Churchill Ltd. 27s. 6d.

The authors of this monograph have drawn from their own wide experience to write a detailed description of the technique of general anaesthesia for neurosurgical patients. The causes and effects of changes in the intracranial pressure, particularly in respect to anaesthesia, are well summarized, while the subjects of radiological investigation and induced hypotension and hypothermia in neurosurgery are fully described.

The wealth of practical detail contained in the chapters on anaesthetic technique will be welcomed by those anaesthetists personally unfamiliar with this specialized branch of surgery, but it is disappointing to find a somewhat superficial account of controlled respiration in relation to neurosurgical practice. Although the authors are renowned protagonists of spontaneous respiration based on a thiopentone, nitrous oxide-oxygen and trichloroethylene technique, yet controlled respirationparticularly with a negative pressure phase-is employed extensively throughout this country, and a more balanced view of it would have been welcome. Despite this criticism, the work provides an interesting and informative survey of anaesthetic practice in a neurosurgical unit and is a useful addition to the literature.

\section{SHAW'S TEXTBOOK OF OPERATIVE GYNAECOLOGY}

Revised by John Howkins. Second edition. Pp. viii +484 . Illustrated. Edinburgh and London: E. \& S. Livingstone Ltd. 1960. £5 5s.

The revised edition of Wilfred Shaw's last book is some 40 pages longer than its predecessor. This does not represent the extent of the changes, for much of the old material has been omitted, including the subtotal hysterectomy and Wilfred Shaw's ' sling ' operation. It is no longer, therefore, a personal anthology, but a standard textbook for the postgraduate student of gynaecology. As such it is right that it should include full descriptions of operations for which there is occasional, but limited, indication; in particular the extended operations for pelvic cancer, which the postgraduate student may see only occasionally and never practise himself. The new edition does this in full. These operations are fully described and well illustrated.

Other new operations which are described include those associated with the names of Green Armytage, Shirodkar, Everard Williams and the late Sir Archibald McIndoe.

In addition, there are new chapters dealing with special investigations, such as colposcopy, the present state of opinion with regard to Bowen's disease and the management of genital tuberculosis. There is an excellent chapter on radiotherapy by Mr. I. G. Williams.
Perhaps the chief criticism is one that may levelled at the first edition also. A book written b] sürgeons with a wide general background may cons tain a tacit assumption of a similar background in its postgraduate readers, whereas many of those why: now proceed to the M.R.C.O.G. do so with a backs? ground of six months' residency in general surgerg only. Those sections dealing with general principless and related specialties could be more explicit an sometimes more complete, for specialist advice is nat always immediately to hand.

Nevertheless, this edition must be regarded as an improvement on its predecessor, because it is morg comprehensive and no longer represents one man's. opinion only. It may be recommended to post graduate students of gynaecology.

\section{A HANDBOOK OF DISEASES OF THE SKIÑ}

By H. O. MAckey. Sixth Edition. Pp. 263

Illustrated. Dublin: C. J. Fallon Ltd. 1960 8s. 6d.

In these days when publishing costs are high is gratifying to see that a well-illustrated textboog of dermatology can still be produced for as little. as 8s. 6d. It follows the general format of thes previous edition and by substituting new materiag for old the book has not been materially altered i length. In the three years since the appearancesos the eighth edition important advances in therapos have made extensive revision necessary in many chapters. However, it is sad to see the author siff advocates bed rest and elevation of the limbōas being the desirable first stage in the treatmentof varicose ulcers and prefers the generally out? moded if time honoured Unna's paste dressings to their now widely accepted successors, the readyo made gelatin bandages of the 'Viscopaste' typeo Although pinch grafts and Thiersch grafts were formerly advocated by many surgeons, few would still recommend them, as does Dr. Mackey, as 9 treatment of choice. Most would lay far less stress than he does on the value of sclerosing injections for varicose 9eins. He ignores the now established techniques of compression bandaging that will heal almost every varicose or thrombotic. ulcer, however large, without the necessity for be rest or skin grafting, providing the dandages are. applied by a doctor or nurse experienced in this method of treatment.

While it is good to see a 12-page section at the end of the book dealing with the nursing of skip diseases, it is difficult to imagine why, under the heading of chronic infective dermatoses, there has been included lupus erythematosus side by sid\% with tuberculosis, syphilis and leprosy.

The index is extensive, but a number of inaccu瓷 racies in page references are to be deprecated.

As the textbook is obviously designed for the student and practitioner without special experienee of dermatology it would be a great deal mors valuable to both if only the most successful methods? of treatment were given as many alternativio methods only confuse the reader. 